Tropical Journal of Pharmaceutical Research October 2012; 11 (5): 695-702

(c) Pharmacotherapy Group,

Faculty of Pharmacy, University of Benin

Benin City, 300001 Nigeria

All rights reserved.

Available online at http://www.tjpr.org http://dx.doi.org/10.4314/tjpr.v11i5.1

Research Article

\title{
Formulation and Optimization of Celecoxib-Loaded Microspheres Using Response Surface Methodology
}

\author{
MK Shahzad ${ }^{1}$, M Ubaid $^{1,2}$ and G Murtaza ${ }^{2 *}$ \\ ${ }^{1}$ Faculty of Pharmacy, Bahauddin Zakariya University, Multan, ${ }^{2}$ Department of Pharmaceutical Sciences, COMSATS \\ Institute of Information Technology, Abbottabad, Pakistan.
}

\begin{abstract}
Purpose: To employ response surface methodology (RSM) for statistical optimization of formulation factors in the preparation of celecoxib-loaded microspheres.

Methods: Celecoxib microspheres were prepared by solvent evaporation method. Biodegradable/biocompatible polymers, Eudragit L-100 and polyvinyl pyrrolidone, were used in the encapsulation procedure. A central composite design employing Stat-Ease design Expert ${ }^{\circledR}$, version 7.0.3 having a unit value of $\alpha$ was used according to reference protocols to assess the influence of two independent variables (i.e., the concentration of the two polymers used) on four dependent variables (i.e., recovery, encapsulation efficiency and \% drug released). The polymers used were Eudragit-L100 $\left(X_{1}\right)$ and polyvinyl pyrrolidone $\left(X_{2}\right)$. The microspheres were characterized for size, shape, recovery (\%), entrapment efficiency and drug release.

Results: The recovered total weight of microspheres ranged between $49.4 \pm 3.1$ and $91.1 \pm 4.8 \%$, and it decreased with increase in the concentration of PVP. Entrapment efficiency was in the range of $54.1 \pm$ 2.9 to $95.6 \pm 3.7 \%$, and was also dependent on polymer concentration. The release of celecoxib increased with decrease in Eudragit L-100 concentration and increase in PVP concentration. Higuchi model was the best-fit drug release from all the formulations. Korsemeyer-Peppas release exponent ( $n$ ) indicates that drug release pattern was non-Fickian diffusion.

Conclusion: Using RSM, it is possible to optimize the drug release properties of celecoxib-loaded microspheres. A celecoxib-loaded microsphere formulation with optimum recovery, entrapment efficiency and release behavior was proposed.
\end{abstract}

Keywords: Celecoxib, Eudragit L-100, Polyvinyl pyrrolidone, Response surface methodology, Microspheres. 


\section{INTRODUCTION}

Response surface methodology (RSM) is a collection of mathematical and statistical techniques for the modeling and analysis of problems in which a response of interest is influenced by variables and the objective is to optimize this response [1]. It has been applied to pharmaceutical systems and particulate carriers such as gelispheres, matrices and microspheres. It is necessary to have a clear understanding of how preparation conditions and inherent characteristics of excipients employed in pharmaceutical preparations are influenced by potential interaction between various factors in order to optimize a formulation $[2,3]$.

Formulations based on microspheres provide optimum control of kinetics of drug release from the dosage form [4]. Controlled release preparations are preferred as these produce maximum therapeutic effect with a low risk of adverse effects [5]. Biodegradable polymers degrade within the body as a result of natural biological processes, and therefore, there is no need to eliminate the delivery system after its function is over [6]. Hence, microspheres made with biodegradable polymers, are useful as controlled release (CR) systems. Several methods are being used for the preparation of microspheres both from natural and synthetic polymers [7].

Celecoxib is used for pain, osteoarthritis, rheumatoid arthritis, painful menstruation and to reduce the number of colon and rectal polyps in patients. It is approximately $10-20$ times more selective for COX-2 inhibition than COX-1 [8-10].

The aim of this study was to prepare an optimized microparticulate formulation of celecoxib employing solvent evaporation technique to elaborate the influence of specific combinations of two polymers, i.e. Eudragit L-100 and polyvinyl pyrrolidone, on the release behavior of the drug. Since RSM with polynomial equations is helpful in the rapid development of an optimum formulation with minimum number of experiments for the investigation of the influence of the independent variables on results, this approach was employed in this study to obtain an optimized microparticulate formulation of celecoxib as well as to assess the effect of specific combinations of two polymers.

\section{EXPRIMENTAL}

\section{Materials}

Celecoxib (99.8 \%) and Eudragit L-100 were donated by IRZA Pharmaceutical, Lahore, Pakistan. Polyvinyl pyrrolidone (PVP) was a gift from Pharma-wise, Lahore, Pakistan, respectively. All other chemicals used - light liquid paraffin (BDH, UK), acetone and $\mathrm{n}$ hexane (Merck, Germany), and Tween 80 (Sigma, USA) - were of analytical grade.

\section{Preparation of microspheres}

Microspheres were prepared by solvent evaporation technique. Different ratios of Eudragit L-100/polyvinyl pyrrolidone (PVP) were dissolved in $40 \mathrm{ml}$ acetone using a magnetic stirrer. Celecoxib was dispersed in the polymer solution and stirred for $15 \mathrm{~min}$. The resulting dispersion was mechanically added in a thin stream to a mixture of $360 \mathrm{ml}$ light liquid paraffin, $0.5 \%$ Tween- 80 and 40 $\mathrm{ml} \mathrm{n}$-hexane contained in a $500 \mathrm{ml}$ beaker. Stirring at $700 \mathrm{rpm}$ was continued for $3 \mathrm{~h}$, until the acetone evaporated completely. The microspheres formed were collected by filtration on Whatman filter paper no. 1 and washed 4 - 5 times with n-hexane [11]. The product was then air-dried at room temperature for $12 \mathrm{~h}$. Formulations were coded as F1, F2, F3, F4, F5, F6, F7, F8, F9, $F 10, F 1, F 12$ and $F 13$, respectively, as per Table 1. All the batches were prepared in triplicate $(n=3)$. The experiments were performed in random order. 
Table 1: Factor combination, based on experimental design, for microsphere formulations

\begin{tabular}{cccc}
\hline \multicolumn{2}{c}{$\begin{array}{c}\text { Coded } \\
\text { factor level }\end{array}$} & $\begin{array}{c}\text { Formulation } \\
\text { code }\end{array}$ & $\begin{array}{c}\text { Drug/Eudragit/ } \\
\text { PVP ratio }\end{array}$ \\
\cline { 1 - 2 } $\mathrm{X}_{1}$ & $\mathrm{X}_{2}$ & & \\
\cline { 1 - 2 }-2 & 0 & $\mathrm{~F} 1$ & $2: 2: 5$ \\
-1 & -1 & $\mathrm{~F} 2$ & $2: 4: 3$ \\
-1 & 1 & $\mathrm{~F} 3$ & $2: 4: 7$ \\
0 & -2 & $\mathrm{~F} 4$ & $2: 6: 1$ \\
0 & 0 & $\mathrm{~F} 5$ & $2: 6: 5$ \\
0 & 2 & $\mathrm{~F} 6$ & $2: 6: 9$ \\
1 & -1 & $\mathrm{~F} 7$ & $2: 8: 3$ \\
1 & 1 & $\mathrm{~F} 8$ & $2: 8: 7$ \\
2 & 0 & $\mathrm{~F} 9$ & $2: 10: 5$ \\
0 & 0 & $\mathrm{~F} 10$ & $2: 6: 5$ \\
0 & 0 & $\mathrm{~F} 11$ & $2: 6: 5$ \\
0 & 0 & $\mathrm{~F} 12$ & $2: 6: 5$ \\
0 & 0 & $\mathrm{~F} 13$ & $2: 6: 5$ \\
\hline
\end{tabular}

Table 2: Translation of coded levels in actual units

\begin{tabular}{llllll}
\hline Coded levels & $\mathbf{- 2}$ & $\mathbf{- 1}$ & $\mathbf{0}$ & $\mathbf{1}$ & $\mathbf{2}$ \\
\hline $\mathrm{X}_{1}:$ Eudragit-L100 & 2 & 4 & 6 & 8 & 10 \\
$\mathrm{X}_{2}:$ PVP & 1 & 3 & 5 & 7 & 9 \\
\hline
\end{tabular}

\section{Experimental design}

A central composite design having a unit value of $\alpha$ was applied according to reference protocols [12] to assess the influence of two independent variables (i.e., the concentration of the two polymers used) on three dependent variables [i.e., recovery $\left(Y_{1}\right)$, encapsulation efficiency $\left(Y_{2}\right)$ and percent drug released $\left.\left(Y_{3}\right)\right]$. The polymers used were Eudragit-L100 $\left(\mathrm{X}_{1}\right)$ and polyvinyl pyrrolidone $\left(X_{2}\right)$. All other formulation and process parameters were kept constant during the study. Stat-Ease design Expert ${ }^{\circledR}$, version 7.0.3, was employed to generate and evaluate the statistical experimental design and construction of a design matrix with 13 experimental trials. The response variables were evaluated by following second order polynomial model, as in Eq 1

$Y=\beta_{\circ}+\beta_{1} X_{1}+\beta_{2} X_{2}+\beta_{3} X_{1} X_{2}+\beta_{4} X_{1}^{2}+\beta_{5} X_{2}^{2}$

where, $\beta_{0}-\beta_{5}$ represents regression coefficients, $X_{1}-X_{2}$ the studied variables and
$Y$ the measured response with each factor level combination (Table 1). Variable combinations selected on the basis of the experimental design and translation of coded levels in actual units are given in Tables 1 and 2 , respectively.

\section{Morphology and size of microspheres}

Optical microscope (Erma, Japan) fitted with a digital camera (Yashica, Japan) was used to measure directly the size of 200 microspheres by taking their photographs and then evaluating the mean diameter [13]. Scanning electron microscope (Hitachi, Japan) was employed to determine external morphology by mounting the microspheres on the stubs, applying thin coating of gold and taking the photographs (operating voltage $15 \mathrm{KV}$ and working distance $20 \mathrm{~nm}$ ) [13].

\section{Recovery of microspheres}

After preparation, the microspheres were recovered and dried overnight at room temperature. Recovery is the ratio of the weight of microspheres recovered to the total weight of solid ingredients charged at the beginning of the process, expressed as a percentage [13].

\section{Drug loading}

The dried microspheres (50 mg) were dispersed in $10 \mathrm{ml}$ phosphate buffer ( $\mathrm{pH} \mathrm{6.8)}$; it was placed in an ultrasonic bath for 15 min and then filtered through a $0.22 \mathrm{~mm}$ millipore filter (Suzhou Hyford Machinery Company, China). The absorbance of the filtrate was taken at $251 \mathrm{~nm}$ using a UV/Vis spectrophotometer (model 1601, Shimadzu, Japan) to determine the amount of celecoxib present in the microspheres. Drug loading was determined as the ratio of the amount of drug in the microspheres to the weight of the microspheres, expressed as a percentage [13].

Trop J Pharm Res, October 2012;11 (5):697 


\section{Entrapment efficiency}

Entrapment efficiency can be determined as the ratio of actual drug loading to the theoretical drug loading, expressed as a percentage.

\section{In vitro drug release study}

In vitro release studies on the drug-loaded microspheres were carried out both at gastric and intestinal $\mathrm{pH}$, i.e., $\mathrm{pH} 1.2$ and 7.4, respectively [14] using United States Pharmacopeial (USP) paddle method. The microspheres $(700 \mathrm{mg})$ were placed in 900 $\mathrm{mL}$ dissolution medium and tested first in $\mathrm{HCl}$ buffer $(\mathrm{pH} 1.2)$ for $2 \mathrm{~h}$ and then in phosphate buffer $(\mathrm{pH} \mathrm{7.4)}$ for $12 \mathrm{~h}$. The temperature was maintained at $37.0 \pm 0.5{ }^{\circ} \mathrm{C}$ and the stirring speed at $100 \mathrm{rpm}$. Samples $(3 \mathrm{~mL})$ were withdrawn and replaced with an equal volume of fresh dissolution medium at regular time intervals, filtered through $0.45 \mu \mathrm{m}$ nylon disc filter (Suzhou Hyford Machinery Company, China) and analyzed spectrophotometrically (model 1601, Shmadzu, Japan) at $254 \mathrm{~nm}$ [14]. The concentration of celecoxib in the samples was determined from a standard calibration) curve. The dissolution studies were carried out in triplicate.

\section{Drug release kinetic analysis}

Drug release kinetics indicates the mechanism of drug release from drug delivery systems. Four kinetic models - zero order, first order, Higuchi and KorsemeyerPeppas represented as Eqs 2 - 5, respectively - were applied to analyze the in vitro drug release data to determine the bestfit release model [13].

$$
F_{t}=K_{o} t
$$

where " $F_{t}$ " is the fraction of drug released in time " $\mathrm{t}$ " and " $\mathrm{K}_{\mathrm{o}}$ " is the zero-order release constant.

$$
\ln (1-F)=-K_{1} t
$$

where " $\mathrm{F}$ " is the fraction of drug released in time " $\mathrm{t}$ " and " $\mathrm{K}_{1}$ " is the first-order release constant.

$$
F_{H}=K_{2} t^{1 / 2}
$$

where " $F_{H}$ " is the fraction of drug released in time " $\mathrm{t}$ " and " $\mathrm{K}_{2}$ " is the Higuchi constant.

$$
M_{t} / M_{\infty}=K_{3} t^{n}
$$

where " $\mathrm{M}_{\mathrm{t}}$ " and " $\mathrm{M}_{\infty}$ " are the amount of drug released at time "t" and " $\infty$ ", respectively, and " $n$ " is the diffusional coefficient. In spherical matrices, if $\mathrm{n}<0.43$, diffusion is Fickian, 0.45 $<\mathrm{n}<0.89$, diffusion is non-Fickian, and $n>$ 0.85 , case-Il (zero order) drug release mechanism dominates [13].

\section{Statistical analysis}

One-way ANOVA was applied to determine the significant difference between various values using SPSS version 15.0. The level of significance was set at $p<0.05$.

\section{RESULTS}

\section{Appearance of microspheres}

The microspheres were spherical in shape with size range of $10.73 \pm 0.97-31.29 \pm$ $1.34 \mu \mathrm{m}$. They were white in color and free flowing.

\section{Recovery and drug entrapment}

The recovered total weight of microspheres ranged between $49.4 \pm 3.1$ and $91.1 \pm 4.8 \%$ and it decreased with increase in PVP content of the formulations (Table 3). Entrapment efficiency was in the range 54.1 \pm 2.9 and $95.6 \pm 3.7 \%$ and was dependent on the concentration of the polymer. RSM results for response $Y_{1}$ (\% recovery) is given in Figure 2. The resultant equation for response $Y_{1}$ is shown in Eq 6.

$Y_{1}=85.6481+2.1358 X_{1}-2.4108 X_{2}-$ $0.2312 \mathrm{X}_{1} \mathrm{X}_{2}-0.0246 \mathrm{X}_{1}^{2}-0.2454 \mathrm{X}_{2}^{2} \ldots .(6)$ 
RSM results for response $Y_{2}$ (entrapment efficiency) is given in Figure 2. The resultant equation for response $Y_{2}$ is given in $E q 7$.

$\mathrm{Y}_{2}=37.0947+1.7348 \mathrm{X}_{1}+13.2304 \mathrm{X}_{2}+$ $0.0375 X_{1} X_{2}-0.1240 X_{1}{ }^{2}-0.9022 X_{2}{ }^{2} \ldots .$. (7)

\section{In vitro drug release}

Drug release from the microspheres depended mainly on the type and concentration of the polymers used in the formulation. Plots of drug release from the microspheres against time are sown in Figure 1. All the formulations displayed sustained release pattern with $18-40 \%$ released at gastric $\mathrm{pH}$ in the first $2 \mathrm{~h}$ and almost 42 to 93 $\%$ released in the next $12 \mathrm{~h}$. The microspheres (F3) containing the highest concentration of PVP showed the fastest drug release with $t_{50 \%}=5.37 \mathrm{~h}$, while the slowest release of celecoxib was observed for F4 $\left(\mathrm{t}_{50 \%}=10.43 \mathrm{~h}\right)$ which contained a higher level of Eudragit-L100 than PVP. RSM results for response $Y_{3}$ (\% drug release) is given in Figure 2. The resultant equation for response $\mathrm{Y}_{2}$ is presented in Eq 8.

$\mathrm{Y}_{3}=5.0553+0.4851 \mathrm{X}_{1}+2.3141 \mathrm{X}_{2}+0.1531$

$\mathrm{X}_{1} \mathrm{X}_{2}-1.3954 \times 10^{-2} \mathrm{X}_{1}{ }^{2}-0.0302 \mathrm{X}_{2}^{2} \ldots$

Table 3: Recovery (\%) and entrapment efficiency (\%) data for microsphere formulations

\begin{tabular}{lcc}
\hline $\begin{array}{l}\text { Formulation } \\
\text { code }\end{array}$ & $\begin{array}{c}\text { Recovery } \\
\text { (\%) }\end{array}$ & $\begin{array}{c}\text { Entrapment } \\
\text { efficiency } \\
\text { (\%) }\end{array}$ \\
\hline F1 & $71.1 \pm 2.6$ & $81.2 \pm 3.7$ \\
F2 & $82.2 \pm 3.4$ & $78.4 \pm 4.9$ \\
F3 & $50.7 \pm 4.3$ & $95.6 \pm 5.4$ \\
F4 & $91.1 \pm 2.2$ & $54.1 \pm 2.5$ \\
F5 & $73.8 \pm 5.5$ & $86.7 \pm 3.7$ \\
F6 & $49.4 \pm 3.6$ & $89.8 \pm 4.9$ \\
F7 & $86.9 \pm 15.7$ & $76.9 \pm 5.3$ \\
F8 & $51.7 \pm 3.9$ & $94.7 \pm 2.5$ \\
F9 & $76.4 \pm 2.3$ & $87.6 \pm 3.7$ \\
F10 & $73.0 \pm 6.5$ & $87.7 \pm 3.8$ \\
F11 & $73.8 \pm 3.2$ & $90.0 \pm 2.9$ \\
F12 & $73.2 \pm 5.4$ & $88.1 \pm 5.2$ \\
F13 & $71.9 \pm 4.6$ & $84.7 \pm 4.3$ \\
\hline
\end{tabular}

For all the formulations, in vitro drug release was best fitted to Higuchi model (Table 3) as the highest linear regression was obtained from this model. Korsemeyer-Peppas release exponent $(n)$ data indicate that drug release mechanism was non-Fickian diffusion.

RSM data for various responses $\left(Y_{1}, Y_{2}\right.$, and $\left.\mathrm{Y}_{3}\right)$ are given in Figure 2.

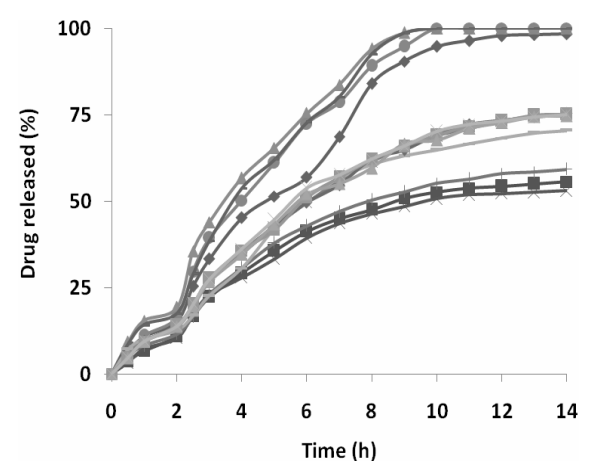

Figure 1: Celecoxib release from the formulations $\leftarrow \mathrm{F} 1 \div \mathrm{F} 2 \div \mathrm{F} 3 \leftarrow \mathrm{F} 4 \div \mathrm{F} 5-\mathrm{F} 6 \div \mathrm{F} 7$ $-\mathrm{F} 8-\mathrm{F} 9 \leadsto \mathrm{F} 10-\mathrm{F} 11-\mathrm{F} 12 \longleftarrow \mathrm{F} 13$

\section{DISCUSSION}

The method used for the preparation of the microspheres successful entrapped celecoxib. Surfactant (Tween 80) used at a concentration of $0.5 \% \mathrm{w} / \mathrm{v}$ was sufficient to facilitate the production of satisfactory microspheres. Attempts made in preliminary studies to use lower surfactant concentrations failed to yield microspheres but rather an aggregated mass was formed. Stirring rate also influenced the recovery (\%). The stirring speed of $700 \mathrm{rpm}$ produced the microspheres of optimum size. By increasing stirring speed above $700 \mathrm{rpm}$, there was low recovery. This low recovery could be due to the formation of smaller microspheres which were lost during washings process. Decreasing the stirring speed promotes aggregation of the microspheres; and causes materials to adhere to the walls of beaker, thus resulting in low recovery. Similar observations have been reported by Giannola et al [15] and Varshosaz and Keihanfar [16]. Increase in Eudragit L-100 content of the microspheres resulted in the significant $(p<$ 
Table 4: Release kinetics of microspheres

\begin{tabular}{lccccccccc}
\hline Formulations & $\mathbf{t}_{\mathbf{5 0} \%}(\mathbf{h})$ & \multicolumn{2}{c}{ Zero order } & \multicolumn{2}{c}{ First order } & \multicolumn{2}{c}{ Higuchi } & \multicolumn{2}{c}{ Korsmeyer-Peppas } \\
& & $\boldsymbol{R}^{\mathbf{2}}$ & $\boldsymbol{K}_{\mathbf{0}}$ & $\boldsymbol{R}^{\mathbf{2}}$ & $\boldsymbol{K}_{\mathbf{1}}$ & $\boldsymbol{R}^{\mathbf{2}}$ & $\boldsymbol{K}_{\boldsymbol{H}}$ & $\boldsymbol{R}^{\mathbf{2}}$ & $\boldsymbol{N}$ \\
\hline F1 & 5.81 & 0.928 & 8.60 & 0.943 & 0.177 & 0.909 & 26.376 & 0.967 & 0.748 \\
F2 & 10.23 & 0.855 & 4.986 & 0.959 & 0.073 & 0.945 & 15.490 & 0.958 & 0.637 \\
F3 & 5.37 & 0.813 & 9.310 & 0.957 & 0.230 & 0.933 & 29.052 & 0.947 & 0.602 \\
F4 & 10.43 & 0.847 & 4.793 & 0.953 & 0.069 & 0.939 & 14.912 & 0.959 & 0.626 \\
F5 & 7.66 & 0.913 & 6.524 & 0.992 & 0.110 & 0.934 & 20.121 & 0.975 & 0.697 \\
F6 & 5.50 & 0.875 & 9.099 & 0.948 & 0.208 & 0.920 & 28.153 & 0.953 & 0.672 \\
F7 & 9.51 & 0.863 & 5.260 & 0.968 & 0.079 & 0.939 & 16.334 & 0.963 & 0.640 \\
F8 & 5.44 & 0.854 & 9.193 & 0.946 & 0.215 & 0.922 & 28.519 & 0.948 & 0.649 \\
F9 & 8.07 & 0.888 & 6.534 & 0.977 & 0.102 & 0.919 & 19.128 & 0.957 & 0.686 \\
F10 & 7.65 & 0.913 & 6.937 & 0.992 & 0.111 & 0.934 & 20.149 & 0.976 & 0.698 \\
F11 & & & & & & & & & \\
F12 & 7.62 & 0.907 & 6.560 & 0.991 & 0.112 & 0.934 & 20.247 & 0.972 & 0.691 \\
F13 & 7.70 & 0.909 & 6.494 & 0.990 & 0.110 & 0.932 & 20.033 & 0.973 & 0.696 \\
\hline
\end{tabular}
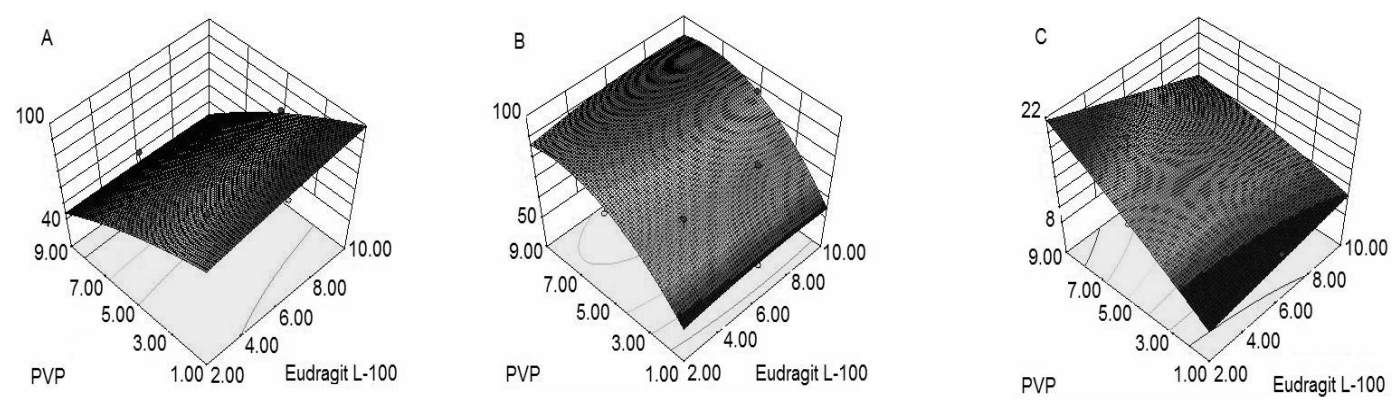

Figure 2: Response surface plots illustrating the influence of polymer concentrations on \% recovery (A), entrapment efficiency $(B)$ and drug release $(\mathrm{C})$

0.05) decrease in entrapment efficiency. This might be as a result of the low drug carrying capacity of the polymer.

Drug release from the microspheres depended mainly on the type and concentration of polymer used in the formulation. Formulation batches F3, F6 and F8 which had a higher concentration of PVP relative to that of Eudragit L-100 showed complete $(100 \%)$ release of drug over the 14 $\mathrm{h}$ period of the release study. A similar result was observed by Babu et al [17] who prepared microspheres using cellulose acetate butyrate and polyvinyl pyrrolidone. PVP is an amorphous polymer and a watersoluble tertiary amine which swiftly dissolves in aqueous environment [17]. It behaves as a strong Lewis base. Being biocompatible, it is widely employed in the fabrication of drug delivery systems. Due to its polar groups, it is an efficient proton acceptor; therefore, it can easily undergo hydrogen bonding with suitable compounds, especially polymers that behave as proton donors. The application of $\mathrm{PVP}$ as polymer matrix has been confirmed to possess significant outcomes, including enhancement of drug stability [17]. Thus, celecoxib release was fastest from formulation F3 which contained which contained a relatively higher level of PVP.

The microspheres with the highest concentration of Eudragit L-100 showed slower $(10.4 \%$ in the first $2 \mathrm{~h})$ drug release in acidic medium $(0.1 \mathrm{~N} \mathrm{HCl})$; however faster 
release $(17.5 \%$ in the next $2 \mathrm{~h})$ occurred in phosphate buffer $(\mathrm{pH} 7.4)$. This implies that Eudragit L-100 provided protection for the microspheres in acidic conditions. Eudragit L100 is a neutral copolymer of polyethylacrylate, methylmethacrylate and trimethylammoniumethylmethacrylate chloride [18]. It is inert to the content of digestive tract, thus does not adversely affect the mucosal lining and is commonly use for the development of oral drug delivery systems [19]. Its degradation is $\mathrm{pH}$ dependent, being sparingly soluble in acidic medium due to the presence of acidic groups such as methacrylic acid [18], but soluble in solution medium of $\mathrm{pH}>$ 6.0. Therefore, it is widely used for targeted delivery of drugs to the colon [19]. It exhibits excellent swelling as a result of which it can retard drug release and is therefore used to achieve prolonged drug release. This probably accounts for the very slow release of celecoxib from formulation $\mathrm{F} 4$ which contained a relatively high concentration of Eudragit L-100.

Higuchi was best-fit model for all the dissolution data indicating that drug was diffusion-controlled. Based on the Korsemeyer-Peppas release exponent (n), drug release was non-Fickian diffusion. NonFickian release, also termed as anomalous release, is a combination of two mechanisms, i.e., erosion and diffusion operating simultaneously [20].

The outcome of the optimization studies indicate that the optimum formulation $(F 10)$ is the one containing Eudragit-L100/PVP in a ratio of $6: 5$. Its recovery and entrapment efficiency $(\%)$ were $73.0 \pm 6.5$ and $87.7 \pm 3.8$ $\%$, respectively. It also showed prolonged release of drug ( approx. $75 \%$ in $14 \mathrm{~h}$ ).

Furthermore, regression equation was a unique model for the description of responses of the experimental parameters employed in the production of the microcapsules.

\section{CONCLUSION}

The results of this study demonstrate that RSM is a valuable optimization tool for selecting suitable variables. Using RSM, an ptimized formulation of celecoxib-loaded microspheres was achieved in terms of \% recovery, entrapment efficiency and release characteristics.

\section{REFERENCES}

1. Bradley N. The response surface methodology. Master of Science Thesis, Indiana University of South Bend, USA, 2007.

2. Choonara YE, Pillay V, Charmicheal T, Danckwerts MP. Studies on a novel doughnut-shaped minitablet for intraocular drug delivery. AAPS pharmSciTech 2007; 8: E1-E7.

3. Mandal U, Gowda V, Ghosh A, Selvan S. Formulation and optimization of sustained release matrix tablets of Metformin $\mathrm{HCl} 500$ mg using response surface methodology. The Pharm Soc Japan 2007; 127: 1281-1290.

4. Khan SA, Ahmad M, Murtaza G, Aamir MN, Akhtar $N$, Kousar R. Dual coated microparticles for intestinal delivery of nimesulide. Latin Am J Pharm 2011; 29: 739-745.

5. Aamir MN, Ahmad M, Khan SA, Akhtar N, Murtaza G, Akhtar M, Rasool F. Fabrication of novel gastro-retentive floating microcapsules by utilizing combination of HPMC and EC and their Physicochemical Assessment. Latin Am J Pharm 2011; 30: 1010-1015.

6. Khan SA, Ahmad M, Murtaza G, Aamir MN, Rasool F, Akhtar M. Study of nimesulide release from ethylcellulose microparticles and drug-polymer compatibility analysis. Latin Am J Pharm 2010; 29: 554-561.

7. Murtaza G. Development of glutaraldehyde crosslinked metronidazole loaded chitosan microcapsules: Analysis of dissolution data using DDSolver. Latin Am J Pharm 2011; 30: 1389-1395.

8. Murtaza G, Ahmad M. Microencapsulation of tramadol hydrochloride and physicochemical evaluation of formulations. Pak J Chem Soc 2009; 31: 511-519.

9. Khan SA, Ahmad M, Kousar R, Murtaza G. Nimesulide-serratiopeptidase sustained release microparticles-Combined formulation and in vitro characterization. Adv Clin Exp Med 2011; 20: 605-611.

10. Yelland MJ, Nikles CJ, McNairn N, Del Mar CB, Schluter PJ, Brown RM. Celecoxib compared with sustained-release paracetamol for osteoarthritis: a series of $n$-of-1 trials. Rheumatol 2007; 46: 135-140.

11. Murtaza G, Ahmad M, Akhtar N, Rasool F. A comparative study of various microencapsulation techniques: Effect of polymer viscosity on microcapsule 
characteristics. Pak J Pharm Sci 2009; 22: 291-300.

12. Tuncay M, Alis SC, Kas HS, Ercan MT, Peksoy I, Hincal AA. Diclofenac sodium incorporated PLGA (50:50) microspheres: formulation considerations and In vitro:in vivo evaluation. Int J Pharm 2000; 195: 179-188

13. Khan SA, Ahmad M, Kousar R, Murtaza G. Nimesulide-serratiopeptidase sustained release microparticles-Combined formulation and in vitro characterization. Adv Clin Exp Med 2011; 20: 605-611.

14. Najib N, Suleiman M. The kinetics of drug release from ethyl cellulose solid dispersion. Drug Dev Ind Pharm 1985; 11: 2169-2189.

15. Giannola LI, De Caro V, Rizzo MC. Preparation of White Beeswax Microspheres loaded with Valproic Acid and Kinetic Study of Drug Release. Drug Dev Ind Pharm 1995; 21: 797807.

16. Varshosaz J, Keihanfar M. Development and evaluation of sustained-release propranolol wax microspheres. J Microencapsul 2001; 18: 277-84.

17. Babu VR, Reddy KM, Sairam M, Subha MCS, Mallikarjuna NN, Kulkarni PV, Aminabhavi TM Des Monomers Polymers. 2007; 10: 155-165.

18. Aceves JM, Cruz R, Hernandez E. Preparation and characterization of Furosemide-Eudragit controlled release systems. Int J Pharm 2000; 195: 45-53.

19. Bikiaris D, Papageorgiou GZ, Stergiou A, Pavlidou $E$, Karavas $E$, Kanaze $F$, Georgarakis $M$. Physicochemical studies on solid dispersions of poorly water-soluble drugs: Evaluation of capabilities and limitations of thermal analysis techniques. Thermochim Acta 2005; 439: 5867.

20. Ansari MT, Haneef M, Murtaza G. Solid Dispersions of Artemisinin in Polyvinyl Pyrrolidone and Polyethylene Glycol. Adv Clin Exp Med 2010; 19: 745-754. 